\title{
GEOGRAFIA E ONTOLOGIA: O FUNDAMENTO GEOGRÁFICO DO SER
}

\author{
Élvio Rodrigues Martins*
}

\section{RESUMO:}

Este trabalho busca a definição do fundamento geográfico como uma das determinações constituintes do ser do homem e da sociedade. Para tanto, retoma alguns dos fundamentos epistemológicos da ciência geográfica, no sentido de redefini-los, e com isso estabelecer novas bases para a relação entre ontologia e Geografia.

\section{PALAVRAS-CHAVE:}

Ontologia, geografia, ser, espaço, tempo.

\section{ABSTRACT:}

This work searchs the definition of the geographic base as one of the constituent determination of the being of the man and the society. For in such a way, it retakes some of the epistemológies basies of geographic science, in the direction of new define them, and with this to establish new bases for the relation between ontology and geography.

\section{KEY WORDS:}

Ontology, geography, being, space, time.

Sempre que se menciona o tema da ontologia no cenário da ciência geográfica, parece que os termos do debate estão apontados. Ou seja, tratar de ontologia em Geografia é remeter a discussão de observar à existência, ou não, de uma ontologia do espaço, mais exatamente do espaço geográfico. Isso num primeiro momento. Em um estágio subseqüente, ocupa-se em definir propriamente os elementos ontológicos constituintes do espaço. Esta reflexão, que ora apresentamos, não segue essa tradição.

$\mathrm{Na}$ tradição, os protagonistas principais deste debate foram e são Armando Corrêa da Silva, pioneiro nessa preocupação, e Milton Santos, este último deixando valiosa contribuição acerca do assunto na primeira parte de seu trabalho A natureza do espaço. É possível citar ainda Antônio Robert Moraes e Ruy Moreira. O primeiro, num único e breve texto já bastante antigo ${ }^{1}$, abandona em momento subseqüente sua posição em favor da possibilidade de uma ontologia do espaço. Já Ruy Moreira, mais recentemente, apresenta uma posição algo distinta dessa tradição com a qual posteriormente, neste trabalho, iremos estabelecer interlocução.

Mas, para começarmos, cabe a pergunta: o que é ontologia? Trata-se de um tema, sabemos, proveniente da filosofia. Ao iniciarmos uma interlocução entre ciência e filosofia, e não querendo fazer aqui a análise da ontologia ao longo da história da filosofia, é necessário mencionar alguns elementos que 
situam a indagação feita.

Identificada como filosofia primeira ou Metafísica, pelo que se observa a ontologia tem início em Parmênides. Este pré-socrático estabelece a necessidade de tomar as coisas em geral enquanto são, as coisas enquanto entes. $\mathrm{E}$ o ente não foi nem será senão o que é, ou seja, o seu ser. Identifica-se assim a essência de todos os entes: o seu ser. Perseguindo a superação socrática dos sofistas, temos Platão integrando ao discurso ontológico a questão da alteridade entre a Idéia e o ente em geral, para nesse caso colocar-nos que a essência, o ser do ente, se encontra na Idéia. Idéia esta que é em verdade um ente metafísico, encerrando o ser das coisas em geral. Em Aristóteles, sem abandonar a posição platônica, temos uma alteração capital, pois mais que ao perguntar pelo ente verdadeiro, derivado do predicado, somos remetidos a indagar-nos sobre o ente enquanto ente. Mais exatamente não mais indagar das propriedades que predicam o ser de determinado ente e, portanto, respondendo quem é este determinado ente, mas sim afirmar dos entes em geral independente de suas predicação específica, ou seja, dos entes enquanto entes. Aristóteles, com isso, estabelece a filosofia primeira, que posteriormente se designará metafísica ou ontologia. Trata-se daquele saber que antecederá os saberes específicos. É nesse de tomarmos os entes enquanto entes, que encontraremos as formas de existência universais desses entes, no sentido de serem gêneros supremos aos quais é possível ao ser se predicar. São as categorias, e entre elas encontramos a substância, a quantidade, o lugar, o tempo etc. Do ponto de vista lógico/gramatical são os gêneros supremos, e do ponto de vista ontológico são as formas elementares da existência. Respondem não o que os entes são, e sim indicam o estar e o ter enquanto condição do existir dos entes em geral².

É muito difícil ser sucinto nesse contexto, mas é necessário este pequeno transcurso, uma vez que ele nos possibilita observar o cenário em que se desenhará a ontologia. Temos agora elementos que precisam ser entendidos mediante suas respectivas relações, tais como existência e essência, ente e ser. Ou então categoria, Idéia, conceito, Substância e matéria.

Já na ciência geográfica, sem ser algo explícito em suas implicações ou declarado abertamente nesses termos, o espaço é tomado como ser, e perfilam-se suas características constituintes. E se espaço é o ser, cabe a pergunta: ser de que ente? É isso que observamos na escassa literatura brasileira dedicada direta ou explicitamente ao tema.

Retomemos o que foi inscrito anteriormente: o espaço é tomado como ser, e é isso o que nos permite as considerações de ordem ontológica. Fica em aberto, entretanto, quem é o ente, que tem como seu ser, o espaço. Pelo menos esses são os termos básicos, como vimos, de um debate que dialoga com preocupações ontológicas. Vale dizer que as perguntas e as posições ontológicas básicas são: o que é o ente como tal? O que significa perguntar-se o que determina o ente como ente, sendo que ele seja o que é, ou seja, qual o ser do ente?

Todo ser é ser de um ente, e é esse ser que determina o que ele é. $O$ ente é o que é em função de seu ser, tornando-se uma Entidade. O ser é condicionante, e o ente o condicionado. O primeiro é determinante e o segundo é determinado. $E$ o ente e seu ser são determinados em sua essência definidora a partir da sua existência. Somos forçados agora a indagar como fica o espaço no lugar da palavra ser, nas perguntas anteriores? Qual existência que define a essência deste ser que o espaço supostamente é? Por assim dizer, no debate geográfico, espaço é um ser de um ente, ou seja, é como se pudéssemos afirmar que um ente é espaço, que seu ser é espaço. Acreditamos que esse conjunto de indagações prenuncia um equívoco subjacente ao debate Geografia e ontologia.

Todavia, mesmo aceitando esse equívoco, em supor o espaço como ser, ou então a indisposição em admiti-lo, essa situação, ao 
nosso ver, não inaugura a dimensão ontológica a ser verificada na ciência geográfica.

O principal equívoco observado está em confundir as dimensões e formas da existência de algo, com esse próprio algo. A existência de um ente é uma coisa que em si pode ser vista e analisada, e outra é o próprio ente em sua constituição. Ou melhor, na existência de um ente coloca-se a constituição essencial desse ente, ou seja, o seu ser. Confundir existência com essência, ou mesmo categoria com conceito, é não discernir entre estar/ter e ser. Ainda que sejam aspectos indissolúveis, e mutuamente determinantes, não podemos confundi-los na definição ôntica do ente, nem na definição ontológica do ser. A existência é a dimensão do estar-aí do ser, sua estrutura relacional e simbiótica com a sua alteridade, ou seja, os outros entes, e é a fonte dinâmica da mutação e redefinição do ser. É o ser-aí, o Dasein de Heidegger. O ser é o que daí deriva como algo posto enquanto essência, uma síntese particular derivada da existência. Portanto, quando atribuímos ao espaço a condição de ser, estamos na verdade definindo aquilo que o espaço não é. Ele é na verdade categoria, e como tal elemento constituinte da existência de um ente e não o próprio ser. Espaço só poderá ser essência enquanto ente ideal, ou seja, como algo diante da Idéia que necessita ser definido. Fora isso, ante os entes materiais ele é categoria, propriedade fundamental de tudo que Existe.

Resta indagar por que a ciência geográfica atribuiu estatuto ontológico ao espaço, lhe conferiu a condição de ser. Mesmo que saibamos que estamos no terreno de uma disciplina científica quando se trata da Geografia, e o debate da ontologia advém da filosofia, a pergunta parece ainda pertinente. Até mesmo porque podemos atribuir a dois filósofos a inspiração que encaminhou alguns geógrafos a introduzirem a questão ontológica na ciência geográfica: o primeiro, e mais importante, é Lukács, e sua "Ontologia do ser social", e o segundo, não diretamente nomeando a questão ontológica para a ciência geográfica, mas certamente fornecendo elementos, é Sartre. O primeiro visível em Armando C. da Silva e Antônio C. Robert Moraes e o segundo em Milton Santos.

Avaliar esse trânsito, da filosofia para a ciência, requer o cuidado de observar o quanto certos conteúdos sofrem alteração no seu significado, mas principalmente tem como meta desfazer equívocos e inconsistências teóricas. Retomar os propósitos da filosofia no ambiente da ciência é colocar esta última em discussão, em todos os seus fundamentos e objetivos, da construção da sua episteme à sua relação com a existência do homem.

Mas a pergunta inicial era: o que levou a ciência geográfica a atribuir ao espaço a condição de ser? Ensaiemos a resposta.

\section{I- Objetividade e Materialidade}

Na ciência geográfica o problema revelase primeiro na coincidência entre matéria e espaço, e posteriormente entre materialidade e objetividade. Podemos observar alguns exemplos dessa superposição, pinçando algumas passagens de obras significativas na formação do pensamento geográfico.

Observemos esta passagem de Ratzel:

É à Geografia Política dada a tarefa de estudar a repartição política dos espaços a cada período histórico, especialmente nos dias de hoje. (RATZEL, 1987, p. 146).

Ou, La Blache:

[...] - porquanto a existência de um denso agrupamento de população, de uma coabitação numerosa de seres humanos num mínimo de espaço, mas que todavia garante à coletividade meios seguros para viver... (LA BLACHE, 1954, p. 37).

Ou então, Sorre:

O espaço geográfico não se caracteriza unicamente pelas dimensões geométricas. Nós, homens, nós o medimos pelas possibilidades de existência que nos oferece. 
(SORRE, 1968, p. 98).

Diante dessas três passagens, erguemos uma pergunta comum a elas: o que é espaço para esses autores? O que é isto que a Geografia política "estuda sua repartição"; ou que "garante à coletividade meios seguros para viver"; ou o que é medido pelas "possibilidades de existência oferecida a nós"?

Creio que a resposta é clara nesta passagem oferecida a nós por Milton Santos:

Natureza e Espaço são sinônimos, desde que se considere a Natureza como uma natureza transformada, uma segunda Natureza, como Marx a chamou. (SANTOS, 1982, p. 10).

Transformada ou não, a natureza aqui é identificada como sendo o espaço geográfico, ou seja, espaço pensado como algo visível externo à consciência e dotado de materialidade.

Mas essa sinonímia tem raízes profundas e longínquas. $\mathrm{O}$ que podemos observar está nas seguintes e importantes passagens:

[...] não há real distinção entre o espaço... e a substância corpórea nele contida, a única diferença reside no modo como estamos acostumados a concebe-los. (DESCARTES, 1995, p. 76).

Somada a essa, temos:

A matéria é o móvel no espaço. O espaço que é também móvel, chama-se espaço material, ou ainda um espaço relativo... (KANT, 1990, p. 25).

No caso de Kant as implicações para Geografia são ainda mais fundas, pois estão relacionadas ao espaço no processo de cognição dos fenômenos. É o que vemos na Crítica da razão pura, e nesse sentido ele é um dado a priori necessário à razão, sem o qual não seria cognoscível esse "espaço material" anteriormente citado. Mesmo essa relação espaço-cognição, é possível observá-la nas citações dos geógrafos mencionados. Todavia não nos deteremos nesse aspecto por hora ${ }^{3}$.
Essas duas últimas citações têm o intuito claro de apontar para as raízes dessa sobreposição. É dentro desse fundamento ainda que insuficiente para tanto - que espaço passa a ser tomado como ser, pois se trata de algo dotado de materialidade, ou mesmo um dado corpóreo. E por ser assim, ele é visível, e mesmo tangível.

Sobre isso objetamos o seguinte: matéria e corpo, ou mesmo natureza, são aspectos distintos entre si e que designam diferentes dimensões da realidade, e o espaço tem outra posição dentro deste cenário, e que não se confunde definitivamente com matéria, corpo ou natureza ${ }^{4}$.

Com isso, discordamos dessa superposição. Na verdade ela remete em grande medida ao disposto por Descartes, como vimos indicado na citação, segundo o qual, tudo depende da maneira como concebemos o espaço. Por exemplo, quando concordamos com a afirmação de que o "espaço é vital", estamos na verdade assinalando o que está contido nele espaço, ou como nos mesmos termos indicamos a importância do território.

Mas, uma coisa é a necessidade de afirmarmos a matéria em sua independência objetiva, ou então a natureza em sua identificação conceitual, e outra é o espaço como uma das formas elementares da existência. É por essa razão que o espaço atinge a condição de categoria, ou seja, daquelas características que se identificam a partir da existência das coisas em geral. Devemos dizer que ao identificarmos o espaço, portanto, não estamos apontando para as coisas em-si, mas sim para uma das formas do Existir dessas coisas. E isso não significa negar o estatuto de objetividade do espaço, ou que o espaço não esteja associado à realidade empírica que nos cerca.

De um lado falamos do ente e sua essência, ou seja, o seu ser, e de outro falamos do Existir deste ente, que fará dele ser o que é. E é exatamente essa distinção que permite ver na existência o fundamento do ser, que por sua vez fará do ente o que ele é, ou seja, o seu 
conceito. Portanto, não posso dizer que as coisas são espaço, ou então que o ente é espaço, e sim que ele, ente, existe, e por existir tem ou está em um espaço, que é uma dimensão e forma da existência do ente. E é essa existência que determinará a essência, o ser do ente. Ou seja, as formas do existir são determinantes na definição do ser em sua essência.

Dito isso, passamos agora a considerar a outra implicação de não confundir e restringir espaço a res extensa. É quando observamos o espaço em seu conteúdo fundante de natureza subjetiva, o que nos remeteria mais uma vez à sua condição de elemento constituinte no ato da cognição do mundo. Caminhamos na direção de afirmar que não existe uma concepção errada de espaço, e sim concepções relativas aos níveis de compreensão da existência que se queira ter do mundo, dos entes em geral. Tomado como uma das categorias da existência, o espaço surge-nos como categoria da ordem. Aquilo que permite verificar as localizações relativas dos entes entre si, e por sua vez sua distribuição, no conjunto de suas correlações, coabitações e, por decorrência, suas codeterminações. Trata-se da categoria que nos remete à ordem das relações das coisas que co-existem. O entendimento dessa ordem equivale em pensamento a um sistema lógico determinado e coerente com essa lógica. Há, portanto, uma relação entre lógica e espaço ${ }^{5}$. De uma lógica que fala da compreensão abstrata da realidade, e de outra lógica que tem a dimensão concreta dessa mesma realidade. De um espaço que denota uma compreensão abstrata da existência das coisas, a um espaço que compreende a dimensão da existência concreta das coisas em geral. Se for possível ver como espaço obedece a uma taxionomia de "agrupamento" ou "ordenação", como é presente no positivismo lógico, é necessário reconhecer que diante de uma outra compreensão do mundo, a noção fundadora de espaço também mude.

Em resumo: a compreensão do espaço e do tempo é a compreensão que temos da existência dos entes.
Assim, espaço é atributo do ato de cognição do mundo. Mas como tal, não é um dado a priori, como queria Kant, e sim algo que emerge como construção social, um atributo cultural, uma forma de ver e compreender o mundo. Sua suposição acompanha diferentes formas de apreensão e compreensão do mundo, além de ser expressão existencial da objetividade das coisas. Nessa perspectiva, encerra dentro de si toda forma de existência e, portanto, de reprodução do mundo.

Reforcemos mais uma vez: não existem, propriamente, concepções erradas de espaço ou de tempo, pois, como dito, elas são coerentes com o que se quer ver sobre o mundo. Se existe algo de "errado", esse limite está sim na qualidade da compreensão que temos do mundo. Visões aistóricas, carregadas de conteúdos ideológicos, situações desse tipo, cada uma delas é sustentada com uma perspectiva equivalente de espaço e tempo. Uma situação perfeita para ilustrarmos o que por último aqui afirmamos, é o caso da geopolítica, nas suas formulações clássicas de "destino manifesto" e coisas dessa natureza.

A única observação em contrário que fazemos quanto às noções de espaço e tempo é quando supomos aquilo que espaço e tempo não são.

Depois disso tudo, ao afirmarmos a improcedência de termos uma ontologia do espaço, repõe-se a pergunta: como fica então a questão ontológica e a Geografia?

\section{II- Geografia e Espaço}

É recorrente observarmos a associação entre espaço e Geografia, e entre tempo e história. Vemos isso desde Hartshorne ${ }^{6}$, consagrando à história o estudo de períodos de tempo e à Geografia seções de áreas do espaço, a Edward Soja, e nesse caso basta observar o seu esforço em Geografias pósmodernas. O que temos aí é a velha e tradicional herança kantiana, que nos chega através de Hettner. Isso pode nos levar na direção das 
disciplinas em questão possuírem tempo e espaço como seus respectivos objetos. Para a ciência geográfica essa posição já é tradicional, mas na história as coisas podem tornar-se, dentro dessa tradição, um pouco mais complexa, pois, diferente do espaço, dentro dessa tradição o tempo não tem materialidade, ou mesmo empiricidade. É o universo da res cogitans, ou como queria Kant, na "Estética transcendental", ser o tempo algo a priori, e serve para por ordem nos sentidos internos. Não querendo estender muito aqui essa reflexão, o fato é que temos outro ponto de vista sobre isso tudo.

Para começar, afirmamos o seguinte: Geografia não é o mesmo que espaço, e possui um conteúdo de significado em que espaço é uma das categorias, entre outras, que a constitui.

Um aspecto fundamental para que entendamos o significado dessa afirmação é a necessidade de distinguirmos a ciência geográfica de um lado, e, de outro - podemos por hora assim anunciar -, a Geografia como um fundamento constituinte e presente na realidade que nos cerca, bem como um fundamento que dá estrutura ao pensamento.

Evidentemente, a partir da ciência geográfica obtemos uma determinada representação, em pensamento, da realidade objetiva que nos cerca. Trata-se de um processo de subjetivação que percorre procedimentos metodológicos. Uma representação subjetiva estabelecida mediante uma sistematização lógica, expressa em uma ou mais linguagens. Isso tudo apontando para os aspectos fenomênicos e essenciais da realidade.

A ciência, assim, mediante seus procedimentos metodológicos estrutura-se em diferentes teorias interpretativas, construindo um arcabouço conceitual e definindo suas principais categorias. A ciência geográfica, portanto, são atos de teoria na prática, de práticas teóricas e no limite representa até mesmo sua institucionalização. A ciência geográfica, quem a faz e a identifica, em diferentes contextos, são os geógrafos. Mas se a prática identifica a disciplina, o que identifica o fundamento dessa disciplina não está na prática. A prática pode muitas vezes se distanciar desse fundamento que consagra a disciplina. E esse fundamento está presente na constituição da realidade, e não necessariamente nas práticas profissionais. É recorrente que no desespero, ou na impotência de identificar o objeto da ciência geográfica, a frase salvadora e revestida de tolerância seja: "a Geografia é o que os geógrafos fazem dela". Isso abre para o espaço "vale tudo", e eventualmente se perde com isso o fundamento geográfico que é presente na realidade. Perde-se isso, e o que é pior, perde-se também a importância e o significado do geográfico na constituição da realidade.

Não saber identificar esse fundamento geográfico é não saber o que é Geografia, ou então confundir isso com a disciplina e suas práticas e institucionalizações.

Quando se identifica esse fundamento geográfico, quando é claro a fenomenicidade geográfica, a ciência geográfica os nomeia de forma diversa. Receberam ao longo da história da disciplina um conjunto de designações, são elas: "fatores geográficos", "fatos geográficos", "elementos geográficos", "aspectos geográficos", "causas geográficas", ou, simplesmente, "o geográfico". Podemos somar a isso "determinação geográfica", ou então falarmos diretamente da "Geografia" da realidade. Ou seja, quando estamos, por exemplo, identificando "elementos geográficos" ou então "determinações geográficas", com isso não estamos apontando para a ciência e sim para a realidade. É como se olhássemos para o mundo e nos indagássemos o que é geográfico nele. Ou, como quem faz a pergunta "onde está o 'fundamento histórico' da realidade?", perguntasse agora onde está o "fundamento geográfico" dessa mesma realidade. Não se está querendo dizer que a geograficidade está lá na realidade, pronta e esperando que alguém a descubra. A realidade externa a nós, não custa lembrar, é indiferente ao sujeito cognocente e é o oposto que ocorre. O nosso existir, e a consciência desse existir enquanto homens, dá- 
se na medida em que designamos, conceituamos a realidade que nos cerca, ou seja, nossa alteridade, o meio. Podemos fundar sua existência e agir sobre ela de maneiras distintas. Mas, neste caldo cultural que é o pensamento científico, a designação a determinadas propriedades do meio que nos cerca levou o conceito de Geografia.

E assim se põe a necessidade de uma ciência que tem como objeto a investigação da geograficidade desse objeto.

Diante dessa assertiva, o que se coloca agora é saber que "objeto" é esse que possui geograficidade, e o que é essa Geografia que se apresenta como propriedade constituinte dele (objeto). Da mesma forma devemos indagar qual a importância dessa propriedade para a constituição e caracterização desse objeto.

A resposta pode vir no examinar da etimologia da palavra Geografia. Ou então, daquilo que outrora era identificado como "estudos ou trabalhos de natureza geográfica", isso quando a disciplina não estava ainda formalizada e devidamente nomeada. Observemos.

Esse "objeto" que possui geograficidade emerge da co-existência e da alteridade do homem em relação ao meio, da sociedade ante a natureza. E a geograficidade é dada num duplo sentido. Dois sentidos que são complementares um ao outro, simultaneamente e não um após o outro. Observamos isso quando na apropriação feita por homem-sociedade, no ato de subjetivar o meio/a natureza, no ato primário da compreensão efetuada pela "descrição". Observe-se aí o fundamento etimológico da palavra "geografia".

Mas como isso ocorre? E que duplo sentido complementar é esse? O que temos é que mediante o ato de descrever dá-se a apropriação do sujeito sobre o objeto. Em íntima e constante relação de se fundar-fundando, se determinar-determinando, a apropriação estabelecida na "descrição" representa simultaneamente um trânsito de mão-dupla da passagem da objetividade à subjetividade. Da senso-percepção imediata até a primeira sistematização fornecida pela Descrição, fundam-se os aspectos "topo-lógicos" e "cronológicos" que serão ordenadores do pensamento, e por sua vez orientadores da ação do sujeito sobre a realidade. Funda-se fundando, e se cria criando. O duplo sentido.

A Geografia nasce, portanto com a relação entre a sociedade e a natureza. É propriedade do homem e é propriedade do meio. Mas é acima de tudo propriedade de um todo, no qual o meio e a natureza são a extensão/projeção do homem e da sociedade na medida em que são criação e representação suas.

Identificado o objeto que possui essa propriedade adjetiva, necessitamos explicitar agora do que se trata exatamente essa propriedade geográfica. Ou seja, essa geograficidade presente nos entes que são fruto da relação homem-meio, sociedade-natureza.

Para isso observemos mais uma vez a o processo que a "descrição" representa. Ela resulta da observação do fenomênico presente na materialidade do mundo que cerca o sujeito. E para que a descrição se realize, enquanto ato expositivo, ela tem de ter para si o sentido da coabitação e do co-pertencimento, considerando com isso a Localização e a Distribuição. Em outras palavras, a descrição demanda um procedimento cognitivo em que, de antemão, as coisas necessitam ser percebidas em sua localização e, por conseguinte, em sua distribuição. É isso que o sentido do geográfico invoca na sua constituição mais básica.

Além disso, a descrição dá conta de uma permanência, que é a das coisas localizadas, e, assim, de uma constância da distribuição. Há aí, portanto, uma duração do observado. Constata assim, a regularidade do tempo de permanência, o que faz supor um equilíbrio. Uma vez que se rompa esse equilíbrio, finda-se a duração, o que significa mudança das localizações, e por sua vez da distribuição. Dáse a sucessão. Na verdade, a sucessão é a 
ruptura do equilíbrio de ritmos presentes numa dada distribuição, ou seja, no perfil das localizações. E os ritmos são ditados pela natureza das relações estabelecidas entre as coisas localizadas, ou seja, distribuídas. Enfim, uma descrição jamais poderá ser estática, ainda que ela dê conta de um momento ${ }^{7}$. Mas o momento é o imediato, e ela, a descrição, supera-se pelo mediato, e isso se dá na relação com a realidade subseqüente, enfim um outro momento. E a Relação estabelece-se como mais uma categoria do existir.

E nesse empirismo imediato, a observação presente na descrição vai denotando a estabilidade/instabilidade das localizações e a constância ou a metamorfose da distribuição. Constata, assim, o grau de mutabilidade do observado, em intervalos de tempo diversos (duração). Ou seja, pela temporalidade e espacialidade, o movimento da realidade realiza-se e é observado.

A descrição fala, portanto, da existência do que vê - a materialidade do mundo, os entes em geral - pelas categorias básicas da existência, tempo, espaço e movimento. Pela descrição, emerge à consciência uma primeira Geografia $^{8}$. A constatação da existência imediata do mundo é dada pela consciência dessa primeira Geografia.

E é neste sentido que podemos ter a Geografia como categoria da existência. Esta categoria que é constituída por espaço, tempo, relação e movimento, estabelecidos a partir da enti(dade) genérica do mundo que é a matéria, e por sua expressão subjetiva, a Idéia. A matéria apresenta-se aqui na unidade processual presente entre homem-meio e na relação entre subjetivo/objetivo. Dentro dessa dinâmica entre subjetivo/objetivo o conteúdo geográfico ganhará forma a partir das noções de absoluto e relativo, contínuo e descontínuo.

E assim, como já foi apontado aqui e ali anteriormente neste texto, podemos também, a partir de agora, designar a Geografia de geograficidade, uma vez que ela se torna fundamento existencial que dá origem aos adjetivos constituintes do ser.

Apresentada a Geografia como categoria da existência, podemos, agora, conferir-lhe a condição de fundamento ontológico, uma vez que a existência tem relação com a definição do ser. A partir disso, a ciência geográfica observa e analisa um fundamento do Existir do ente, fundamento este responsável pela qualidade da essência desse ente, ou seja, a definição do seu ser.

A Geografia passa a ser agora categoria da existência. Revela-se como fundamento ontológico da definição do ser de um ente. Esse ente que é o homem, e sua objetivação, o meio.

Mas antes de dar seqüência a esta reflexão, é oportuno agora iniciarmos a interlocução anteriormente anunciada, pelo menos dar os primeiros passos. Trata-se da posição que Ruy Moreira assume diante deste debate. Como será observado, vamos encontrar algumas diferenças, que não serão encaradas propriamente como discórdia, mas como diferenças que suscitam dúvidas, e nesse sentido deixam em continuidade o debate. Cotejamos três passagens breves do texto "Marxismo e geografia (a geograficidade e o diálogo das ontologias)".

A geograficidade é a existência em sua expressão espacial. O ponto ôntico-ontológico de tradução do metabolismo homem-meio no metabolismo homem-espaço. (MOREIRA, 2004, p. 33).

E a geograficidade é em si a síntese da relação entre essência e a existência e assim a própria totalidade concreta do ser. [...]

A geograficidade é, assim, o ser-estar espacial do ente. É o estado ontológico do ser no tempoespaço. (idem, p. 34).

A primeira coisa a ser dita é que há uma objeção quanto a estabelecer a geograficidade como expressão espacial. O que aqui foi afirmado considerar-se-á constituída por mais que o espaço, e sim um complexo constituído das categorias de tempo, espaço, movimento e relação, isso ante a unidade processual presente 
entre homem-meio, constituída pela relação objetivo/subjetivo. Nesse sentido, ela é expressão superior de uma forma complexa da existência (junto com a História), que certamente responde pela determinação concreta do ser, sendo, todavia, que não é síntese da relação essência e existência. A essência do ser configurar-se-á a partir de determinações geográficas (e históricas), posto que são determinações da existência. O ser do homem se confundirá com a mundaneidade do meio, em que a dicotomia entre homem-meio é superada quando tomamos o nosso ser a partir das nossas objetivações, e de nossas objetivações na construção de nossa subjetividade. Esse ir e vir não é mero jogo de palavras, nem forma prolixa vazia, mas sim a dificuldade da expressão escrita de uma dinâmica viva.

Quanto à segunda sentença presente na primeira afirmação, estabelece-se uma dúvida. Se é ôntico e ontológico, isso nos remete para a relação entre o ente e seu ser. Muito bem. Mas considerar a geograficidade a tradução do metabolismo homem-meio para o metabolismo homem-espaço? Mas na metamorfose homemmeio já não temos espaço (como tempo, relação etc)? Uma vez que espaço não é o mesmo que meio, e que o primeiro só pode ser dado pelo segundo, concluimos que a metamorfose do meio pela ação do homem é seguramente uma alteração nas condições de existência do meio e do próprio homem. O que significa dizer que a geograficidade se alterna mediante a metamorfose operada na relação homem-meio, dando mais uma vez sustentação em considerar o movimento como constituinte da forma complexa de existência que é a geograficidade. Mesmo assim, fica em aberto aqui o entendimento do significado exato dessa passagem.

\section{III- História e Geografia: categorias complexas da existência}

Como fundamentos da existência, em seu complexo dinâmico que é a vida, homem e meio e sua respectiva relação, tem a reflexão completa quando aí inserimos, também, a História, uma vez que esta não é outra coisa que a dinâmica processual em curso na relação entre sociedade e natureza, entre homem e meio. Também ela, a História, se estabelece a partir do movimento, do espaço e do tempo.

Entretanto, há uma diferença entre Geografia e História. E para termos essa diferença devemos observar sua expressão própria nas dimensões do tempo e do espaço.

Enquanto a Geografia é especialmente definida em Ritmos e Durações, a História tem sua temporalidade definida predominantemente nas Sucessões. E a História está na Geografia pela descontinuidade das durações, e a Geografia está na História pela descontinuidade das sucessões. E entre essas descontinuidades encontramos a desigualdade/desequilíbrio que compõe a síntese dos ritmos dos Momentos.

O Tempo Geográfico é a síntese dos ritmos que compõe o equilíbrio/desequilíbrio de um Momento, ou seja, de uma Duração. O tempo da geograficidade surge da velocidade do ciclo rítmico presente nos diferentes aspectos que compõem a relação entre homem e meio, entre sociedade e natureza. Ou seja, aquilo que dá dinâmica à metamorfose da localização/ distribuição.

Pierre George falava-nos que "a noção de tempo geográfico é noção original e difícil de definir. O tempo geográfico é ao mesmo tempo geológico, histórico e contingente." (GEORGE, 1969 , p. 50). George sugeria supormos um tempo sideral composto de tempos comuns, e cada um destes qualificado por tempos anômalos. Sendo que os tempos anômalos são definidos por acontecimentos marcantes, como uma crise, uma guerra, uma revolução, uma catástrofe natural.

A observação é rica, mas o que faz com que as temporalidades mudem não é uma alteração do tempo em si mesmo, mas sim aquilo com o qual o tempo é categoria da existência. Ou seja, os entes modificam-se, movimentamse, metamorfoseiam-se, estão em constante 
processo, porque seguem existindo.

E existir é colocar-se em uma estrutura de relações com outros entes.

As relações são a origem das transformações, pois as relações são processos de co-determinação das partes envolvidas. As relações podem marcar ciclos de duração diversa, ou seja, de ritmos diferentes. Mais exatamente, as relações possuem um ritmo determinado. E num determinado ritmo, podemos observar um ciclo que se completa. Na trama de relações em que um ente está envolvido, os ciclos de cada relação completamse em tempos diferentes, pois os ritmos de cada relação são díspares entre si. O que faz supor que entre os diferentes entes, na totalidade da distribuição, cada um está submetido a uma velocidade em sua metamorfose. $\mathrm{E}$ a distribuição será estável em sua duração até o momento em que o equilíbrio dos ritmos se rompa, compondo com isso uma nova distribuição.

Nas diferentes escalas de relações, na espacialidade diferencial em que o ente se encontra localizado e posto em diferentes distribuições, a geograficidade é móvel. A Totalidade em sua Geografia é o real em processo histórico. Há na verdade um processo geográfico de caráter histórico, pois como queria Herder, a História é uma Geografia em movimento ${ }^{9}$.

O equilíbrio é momento para o pensamento. E como há uma síntese instável estabelecida na relação entre os ritmos, a ruptura desse momento representa uma recombinação da síntese rítmica fundando um novo momento, portanto entre um momento e outro, entre uma duração e outra, a passagem da origem a sucessão. E eis a História.

Há uma descontinuidade temporal presente na distribuição. Pois, cada ente que se localiza, o faz em momentos distintos. Assim, a origem das localizações, essa ordem de coabitações temporalmente distintas, da origem ao espaço histórico, ou seja, originado de permanências desiguais derivadas de

\section{sucessões descontínuas.}

E é nesse sentido que o presente é uma simultaneidade desigual de sucessões e durações, fazendo a história presente, por meio de Geografias do passado, fazendo da história a Geografia em movimento. Uma Geografia que permanece subordinada a outra presente. E nessa força da relação entre a Geografia e a História, observamos a existência do ser, no momento entre o ser e o não-ser. Há na verdade um processo histórico de caráter geográfico.

A existência, o existir é um estar posto de um ser-aí: em uma Geografia, aí em uma História. Uma Geografia que se estabelece como um fundamento ontológico.

\section{IV- O Fundamento Geográfico do Ser}

Agora a geograficidade está aí em sua identidade e diferença. Identidade enquanto subjetivação do apreendido, diferença a partir da realidade em sua história.

Mas identidade e diferença entre o que, ou quem? Entre homem e meio, entre sociedade e natureza. Uma Geografia que será do homem mediante a Geografia do meio, e uma Geografia do meio que só será enquanto relação com o homem.

Está dada aí (no meio) enquanto identificada aqui (no homem, no sujeito), por isso designada. Existe, e Existir é existir para a consciência ${ }^{\circ}$. Mas o que existe é o meio, na medida em que é consciência para o homem. $E$ por existir é que possui Geografia; algo que emergiu da relação entre homem e meio.

Está dada aí, enquanto identificada aqui. E o "aqui" só será possível em sua consciência mediante o "aí", mais exatamente de um "aqui" que será um ser-aí (o Dasein).

Enquanto extensão de si mesmo, do homem, no duplo sentido da apropriação, ao designar a Geografia do meio, ficam estabelecidas as bases objetivas da Geografia do homem. E a Geografia do homem, enquanto 
fundamento ontológico do seu ser, estabelecese como subjetividade. Mas, como exatamente? Como a Geografia será um fundamento na definição do ser do homem, de sua humanidade?

A resposta a isso tem início com uma importante observação. Não tomamos como sinônimo, e acreditamos que marcam diferenças importantes entre si, os pares homem-meio e sociedade-natureza. Ainda que estejam interrelacionados, apontam para dinâmicas específicas, e, portanto respondem a questões próprias. Uma coisa é indagarmos o que é o homem, outra é o que é sociedade, o mesmo se aplica para natureza e meio.

$\mathrm{Na}$ observação dessas diferenças, encaminhamo-nos para a resposta da pergunta feita: como a Geografia será um fundamento na definição do ser do homem, de sua humanidade?

Vamos trabalhar com o par singularidade/universalidade ${ }^{11}$, e observar que estes quatro conceitos (homem, sociedade, meio e natureza) absorvem de forma própria a singularidade e a universalidade. A necessidade de observar mediante a singularidade/ particularidade/universalidade vem do fato de considerarmos "traços essenciais dos objetos da realidade objetiva, de suas relações e vinculações, sem cujo conhecimento o homem não pode nem se orientar no mundo circundante, para não falar em domina-lo e submete-lo a seus fins" (LUKÁCS, 1982, p. 200).

Os grifos são nossos, e destacam a necessidade de ver o quanto é forte a evidência da geograficidade nesses termos.

Diferentemente do que poderíamos em princípio supor, o homem não é a singularidade de uma dada sociedade. Como se de um coletivo de pessoas, um indivíduo seria a singularidade desse coletivo. Não.

Em si mesma uma sociedade se singulariza ante outra sociedade, mediante a identificação de uma específica sociabilidade. Uma sociabilidade singular. Por meio dos elementos universais presentes em toda e qualquer sociedade, vive essa determinada sociabilidade singular, ou seja, a partir daí se tem uma sociedade particular. Não que se possa de falar de uma estrutura comum, ou qualquer coisa do gênero, a toda e qualquer sociedade que se possa denominar sociabilidade universal. Em princípio julgamos que os elementos universais devam ser poucos, e possivelmente estão relacionados à sobrevivência e à reprodução material, conjuntamente com e os atos em si de apropriação aí contidos. Algo como o sugerido nestas passagens por Ratzel:

Em meio a muitas variações que se sobrepõem, as relações entre sociedade e território continuam sendo sempre determinadas pelas necessidades de habitação e alimentação. [...] A alimentação representa a necessidade mais imperiosa tanto para o indivíduo como para a sociedade, pois as obrigações que impõe tanto a esta quanto àquele precedem a todas as outras. (RATZEL, 1914, p. 64-65).

O raciocínio também se aplica ao homem, em que a sociedade não é seu universal, e sim uma determinada humanidade. Há uma humanidade genérica (universal), pela qual vive uma humanidade singular, a individualidade própria de cada homem, do homem particular.

Entretanto, uma sociabilidade singular é humanidade genérica ante o homem particular. Pode-se denominar uma sociabilidade singular de cultura, já o Humano singular é contingente e aleatório, e talvez decorra da psicanálise a possibilidade de melhor o caracterizar. Nessa injunção de cultura e estruturas psíquicas compõe-se a subjetividade de cada indivíduo, a individualidade.

As questões agora são: o que é a humanidade genérica (sociabilidade singular) do homem? E o que é a humanidade singular de cada homem? Em síntese, é formular a questão que é o ser do homem? Ou qual o sentido do seu ser? Eis a questão ôntica: quem é o homem, pois o ente é o homem. Todavia para responder a isso temos que nos remeter à questão ontológica: o que é o ser desse ente, que é o homem. 
Do ponto de vista genérico, ou então universal, somos compostos de uma estrutura bioquímica, definidos uma cadeia de DNA específica, como todos os seres vivos, e processamos constantemente a simbiose orgânico e inorgânico em nome de nossa reprodução e sobrevivência. Mas, o que nos torna únicos diante de outras espécies "únicas" é uma singular estrutura bioquímica e uma cadeia de DNA determinada. Essa situação revela uma biologia determinada, ou seja, uma forma de vida particular.

Entretanto, todas as espécies vivas possuem estrutura bioquímica e cadeia genética. Tomado isso em si mesmo, observamos que tal aspecto não nos singulariza. Todos os seres possuem diferença entre si. Portanto, a questão que se coloca agora é o que nos torna particular diante das demais espécies, ou seja, qual é a singularidade da espécie?

A pergunta o que é o homem não pode mais se dividir entre uma resposta da filosofia e outra da ciência, uma vez que para ambas o que é comum, além da própria pergunta "O que é o homem?", é o fato de que em ambas a indagação é feita pelo próprio objeto da questão. Mais exatamente, quando olhamos a pergunta encontramos dois elementos sumamente importantes: as palavras "é" e "homem", ou seja, o verbo ser e substantivo homem.

Observemos isso seguindo a sugestão de Heidegger, que em qualquer pergunta podem os distinguir três coisas: 1, o que se pergunta; $2^{\circ}$, aquele a quem se pergunta ou que é interrogado; $3^{\circ}$, aquele que pergunta. Na nossa pergunta quem pergunta é o homem, um ente que se indaga sobre o seu ser, sendo ao fazê-lo, representa que o próprio ser se pergunta sobre si mesmo.

Portanto, o que exatamente nos singulariza como espécie é esse fundamento ontológico, que juntamente com nossa universalidade biológica nos coloca como realidade particular.
Entretanto, todos os homens, indistintamente, são assim genericamente: uma síntese entre o biológico e o ontológico, e eis aqui, mais uma vez, o particular tornando-se universal. Todos os homens são o complexo bioontológico.

Daí deriva a indagação: o que singularizaria cada homem dentro do universo genérico da espécie? Ou seja, o que faria dele uma unidade singular, um indivíduo. A resposta: a sua escolha, o seu remeter-se para a vida, as necessidade de superação, que para além da sobrevivência agora será existência.

Um ser-aí, um ser-no-mundo, um ser projetado no mundo. Um ser de um ente, $O$ homem e sua relação com o meio. "Meio" que é sua alteridade, que é sua mediação para a formação da identidade e da diferença, o universo da interação que estimulará sua escolha individual. A escolha é a apreensão, a apropriação, a compreensão, a interpretação, o juízo, a Lógica, enfim, é um ato gnosiológico. É a representação, é subjetivação. É também a condenação à liberdade de Sartre, ou o Cuidado de Heidegger. O homem passa a ser-indivíduo, ou seja, nasce a Individualidade.

Agora vemos que todos os homens particulares são assim. Constituem-se por um complexo bio-ontológico, e particularizam-se por uma singular escolha. Todos processam a escolha.

E isso é muito importante, uma vez que a escolha projeta o homem para fora de si. A escolha lança o homem ao mundo. Rigorosamente o põe no mundo, o que significa estar-no-mundo. O que remete ao sentido do ser-aí, o que para a ciência geográfica soa mais costumeiramente como a relação homem-meio.

Acrescente-se a isso que estar-nomundo é estar em um mundo determinado, meio pelo qual o homem se vê impelido à escolha. Essa determinação do meio é definida em função de ser meio constituído na relação com o homem, ou melhor, é meio determinado em sua especificidade a partir da alteridade 
condicionante que é o homem. Não se trata de "qualquer meio", mas meio específico correspondente a um específico homem.

Por sua vez, a escolha é dependente do conjunto de relações que ele homem se vê posto com o meio. Assim, o que determinará a especificidade da escolha, que definirá o projeto, o cuidado e a representação, será a natureza das relações daí derivadas, consubstanciando a sobrevivência e a existência. O ser estará sendo definido nessa estrutura de relações que é a existência. Em outras palavras, a escolha se define ante uma específica sociabilidade. Todavia, ainda que em estreita relação de determinação, a escolha como ato singular de homem é revestida de aleatoriedade na sua definição, se assim não fosse, estaríamos eliminando a individualidade do processo.

Para Heidegger, a existência nessa situação apresentada teria caráter inautêntico. Para ele não seria nesses termos do "Cuidado" das coisas em geral, ou mesmo de outros entes, em que o ser encontraria o seu sentido revelado. O ser-aí condenado à sociabilidade estaria imerso nela, e situando-se diante dela mediante uma estrutura de relações, na qual se medem distâncias pelo caráter utilitário que possuem as coisas em geral. E é nessa estrutura de relações que se baseia a existência e a noção de espaço em Heidegger. Nosso diálogo crítico com as idéias desse filósofo, que será mais bem sistematizada em outra oportunidade, começará exatamente neste ponto, para posteriormente considerar sua posição na qual a existência é autêntica, aquela que permite a busca do sentido do ser, mais exatamente no viver para a morte, dando ao tempo, a História, essa prerrogativa ontológica. Como veremos a questão não está na autenticidade ou inautenticidade da existência, em função dos projetos existenciais aos quais o homem se coloca. O sentido do ser, ou então a sua essencialidade, vê-se obliterado no seu conteúdo por meio de outro processo, a saber a Alienação, e as situações daí decorrentes, a coisificação, o processo fetichização e, finalmente, o estranhamento. Mas para chegarmos a entender o contexto em que esses elementos se inserem, é necessário darmos mais um passo no processo que estamos expondo.

Retomando, como foi anunciado linhas atrás, a escolha define-se ante uma específica sociabilidade, e isso significa observar pela primeira vez a relação entre homem e sociedade, entre a individualidade e a sociabilidade.

Em resumo, agora temos que todos são uma construção de um complexo bio-ontológico dotado da Escolha, que é determinada por uma específica sociabilidade, e que essa sociabilidade advém de determinadas relações com os outros homens e o meio. Eis aí, portanto, agora nosso novo universal, o que nos coloca na direção de indagarmos o que torna singular a estrutura da existência. O que faz de uma sociedade algo distinta, para que ela determine a Escolha de cada homem?

A resposta está em observar as formas de organização social que fundam sobrevivência da sociedade, ou seja, o Trabalho. O Trabalho que é o superlativo momento em que se fundem sobrevivência e existência, no qual se processa a relação entre subjetividade/objetividade.

Nessa direção observemos as seguintes passagens, os grifos na seqüência são nossos:

A visão direta de modos de existência estreitamente relacionados com o meio, eis a novidade que fazemos à observação sistemática das famílias mais isoladas, mais atrasadas da espécie humana. (LA BLACHE, 1954, p. 36).

Mais adiante ele acrescenta:

[...] podemos compreender como certos homens, colocados em certas e determinadas condições de meio e agindo conforme a própria inspiração, procederam para organizar sua existência. (ibidem).

Firme e cristalina é também a posição de Pierre George sobre o assunto. Numa linha de 
encadeamento, atrela de forma direta a questão da Existência ao Trabalho, este visto como "meio de assegurar a existência, sob designação existência deverão ser examinadas todas as modalidades da vida - ativa ou passiva - alheias ao exercício de uma atividade profissional ou situadas ao nível mais elementar de uma atividade de produção determinada a satisfazer as necessidades do consumo cotidiano" (GEORGE, 1969, p. 133). Há também a preocupação em observar a sujeição que as modalidades do trabalho influam sobre a vida dos indivíduos como um todo e nessa perspectiva a questão da existência é discutida em termos de Habitat e Habitação.

O que cabe dizer agora é que na verdade estes geógrafos confundiram existência com sobrevivência. A sobrevivência é a dimensão material da existência. A sobrevivência é a relação orgânico-inorgânico. É seguramente do Trabalho que devemos falar. Mas não nos termos delimitados por Pierre George, ou seja, trabalho definido em função dos condicionamentos bioclimáticos, ou caracterizado por seus fatores técnicos ou mesmo econômicos. Devemos ir além, na direção de ver no Trabalho o ato de autoprodução do homem, ou seja, da definição de sua humanidade, da definição do seu complexo bio-ontológico, passando ser a atividade por meio da qual, e na qual, somente o homem se torna aquilo que ele é como homem, segundo sua essência.

O autor das idéias dessas últimas linhas é Marx, talvez nem fosse necessário dizê-lo, mas é o rumo que esta reflexão se inspira. Convém, portanto, reafirmar o fato de que se o Trabalho representa o ato de objetivação da essência humana, e assim produz o mundo (meio) e ao homem em sua humanidade. Dentro dessa perspectiva ele, o Trabalho, é compreendido como categoria filosófica. E se a economiapolítica se faz necessária é porque ela traduz nos termos da sobrevivência aquilo que a filosofia(ontologia) exige para explicar a existência e por conseguinte o ser do homem.

Portanto, a existência remete à subjetivação em essência da sobrevivência, na constituição, portanto, do ser. Na sobrevivência dá-se o trabalho, e na existência dá-se a subjetivação deste. A sobrevivência define por base uma existência, e esta representa a subjetivação, a constituição do ser, ou seja, define um Gênero de Vida.

Estamos voltando a essa velha categoria da ciência geográfica. Como definia Max. Derruau, o Gênero de Vida é "o conjunto de hábitos pelos quais o grupo que os pratica assegura sua existência" (DERRUAU, 1964, p. 169).

Todavia, vamos levar essa definição efetivamente para o horizonte da existência, ou seja, não considerar apenas a sobrevivência, e com isso, finalmente, encontrar o fundamento geográfico do ser. Isso porque essa categoria reúne os principais elementos do debate ontológico: homem-sociedade-escola-trabalhonatureza-meio.

Diante dessa ampliação do conteúdo da categoria Gênero de Vida, considerando-a agora como a relação entre sobrevivência e existência, chegamos ao aí do ser-aí, ou seja, a sobrevivência e a existência exigem a relação entre o homem e o meio, entre a sociedade e a natureza, para que se realize a escolha, e para que esta se defina no trabalho. Cada homem é um conjunto onto-biológico, destinado a uma escolha, escolha esta amparada pelas determinações da sobrevivência, ou seja, pelo conjunto de relações homem-homem/homemmeio regidas pelas formas do trabalho.

Genericamente todos os homens estão nessa construção, pois é a condição inescapável do ser-aí, e isso nos remete a estarmos diante do universal. E as perguntas, agora, são as seguintes: o que virá a ser singularidade, que estará a viver por meio dessa universalidade que funde o ontológico e o biológico, a sobrevivência e a existência?

A resposta está primeiro em reconhecer que, nestas alturas, História e a Geografia já se firmaram como categorias da existência, vale, 
ainda, dizer que a existência realiza-se em uma História e em uma Geografia. Diante disso procurar responder sobre as singularidades possíveis dentro dessa universalidade anteriormente anunciada é buscar identificar Histórias singulares e Geografias singulares, ou seja, a dinâmica de um Cotidiano específico, inscrita em um respectivo Habitat específico. O que estamos dizendo que a existência do homem concreto é o cotidiano, dada numa Geografia específica, estabelecida em um Habitat determinado.

Na ciência geográfica quem tratou do Habitat foi Maximilen Sorre em primeiro lugar, e na seqüência Pierre George. Para eles o sentido dessa categoria vem associado ao Gênero de Vida, e assim os elementos que aqui nos interessam começam a se encontrar:

- o Gênero de Vida que para os geógrafos aparece como existência, quando na realidade estão a considerar sobre a sobrevivência;

- operamos a redefinição da categoria Gênero de Vida, considerando a subjetivação do ato de reprodução material da sociedade, ou seja, efetivamente tomamos em consideração a existência;

- encontramos em Sorre a associação entre gênero de vida e sua expressão geográfica a saber, o Habitat.

O que vemos em Sorre é o fato de que o Habitat se tipifica segundo o gênero de vida. Sorre mesmo diz que as formas do Habitat são as "expressões concretas mais características dos gêneros de vida" (SORRE, 1984, p. 122). Assim, considerando exclusivamente os elementos da relação sociedade-natureza, que garantem a sobrevivência (produção e reprodução) material, o habitat é definido como habitat rural, ou formas de transição para urbano, habitat urbano propriamente e, finalmente, habitat urbano em forma evoluída, ou seja, as grandes cidades.

A sugestão de Sorre é estimulante, mas deve ser aprofundada, e nesse sentido é interessante observar o que escreveu Pierre
George, acerca de Max Sorre, em decorrência de seu falecimento, nos Annales de Géographie. A citação é um pouco longa, mas vale a pena:

Com a organização do trabalho em série, nascido do aperfeiçoamento da maquinaria, com a automatização, surgiu um novo mundo de trabalho. Os economistas, os dirigentes de indústrias falam de rendimentos, de eficácia de trabalho; o sociólogo sabe que se trata de outra coisa, de uma revolução profunda nas relações dos homens entre si e com as coisas e que esta revolução atinge o recôndito dos homens. A ligação está feita entre a Geografia Humana e a sociologia global de um lado e da sociologia da vida cotidiana de outro. Max Sorre faz diretamente alusão às "belas obras de George Friedmann", mas não se poderá esquecer sua frutuosa colaboração com George Gurvitch, e seu apelo a sociologia da vida cotidiana e da modernização que introduz para o geógrafo - estudo da obra de Henri Lefebvre. (GEORGE, 1967).

"E que esta revolução atinge o recôndito dos homens", ou seja, o ser do seraí. Esse gênero de vida que aí emerge e que possui um Lugar com uma História expressa em uma Geografia determinada.

Nos termos anunciados, o caminho para identificarmos o fundamento geográfico do ser já está demarcado. Por necessidade de identificarmos o Lugar, impõe-se o conteúdo do Rural e o conteúdo do Urbano, uma vez que este se estabelece em função de um gênero de vida, e a partir disso o caráter de uma existência. Enquanto fenômenos geográficos de expressão imediata, cidade e campo passam a ser avaliadas em sua relação e consubstanciação enquanto Geografia rural ou Geografia urbana. O Lugar como totalidade, reunindo o singular e o universal, é a particularidade necessária para identificarmos o fundamento geográfico do ser. O espaço urbano e o espaço rural na condição de universais devem encontrar a singularidade 
que os particulariza enquanto Geografias de um Lugar particular.

E, do ponto de vista do cotidiano, as Geografias do urbano e do rural são contextos escalares dos quais necessitamos de uma precisão maior para identificarmos o fundamento geográfico do ser do homem particular. E diferente do que ponderava Pierre George, uma cidade pode abrigar diferentes habitats, pois cada vida cotidiana é particular na medida que comporta em si aspectos únicos e singulares. Como anunciou Heller "la vida cotiana es el conjunto de atividades que caracterizan la reproducción de los hombres particulares, los cuales, a su vez, crean la possibilidad de la reproducción social" (HELLER, 1987, p. 19). O habitat, nesse sentido, é o espaço de vida, o espaço vivido pelo indivíduo, a realização imediata da existência, é a relação imediata do homem com o meio, o ser-aí em sua mais in ediata Geografia, é sualocalização. O Lugar do ente em seu ser-aí.

Chegamos a um ponto extremamente importante: a Localização. E diante disso duas situações a serem observadas: a primeira refere-se ao significado do Sentido de Localização para o homem, pois que isso nos permitirá, finalmente, verificar o fundamento geográfico da essência do ser. Ou seja, é na localização que o ser se vê determinado por uma específica Geografia. É quando podemos ver a Geografia como categoria da existência. Portanto, o sentido da localização necessita ser explicitado, e é um sentido que se revela ao responder às perguntas: o que significa estar localizado, pertencer a uma localização? E em seguida, para melhor compreensão da primeira, exige verificar o conteúdo do significado da Localização, ou seja, o que é essa Localização.

A localização não deve aqui ser entendida estritamente a partir das coordenadas geográficas, nos termos de uma cartografia cartográfica propriamente dita. Temos que somar conteúdo, e o conteúdo que perseguimos vai na direção de consubstanciar a idéia de uma cartografia geográfica, na qual a Geografia disposta nessa linguagem se firma fundamentalmente por sua natureza qualitativa. É nessa Geografia que o conteúdo da Localização remete à posição do homem dentro de uma estrutura relacional, dentro de uma estrutura de co-habitações, na qual a distância não é tomada em termos métricoquantitativos, mas sim em termos da intensidade qualitativa da relação. O ente entre entes, inserido numa estrutura de cohabitações, presente, portanto, num contexto de uma Distribuição, que coloca uma localização específica numa trama escalar, de Extensão determinada. E assim o sentido da localização se definirá pela intensidade qualitativa da relação e pela extensão a que se vê inserido o ente. Extensão e intensidade qualitativa numa relação variam em função de aspectos que vão desde a afetividade (identidade, sentimento de pertencimento etc.) até o caráter técnico estabelecido na relação, e neste último caso sugere observar no limite até mesmo seu conteúdo tecnológico. Nesta discussão toda, exatamente aqui é possível vislumbrar o fundamento empírico disso tudo.

Assim, o Sentido de Localização representa para o ente sua "porta de entrada" para a Geografia a qual este pertence, ou qual a Geografia que lhe é presente, ou enfim qual a geograficidade que Ihe é fundante e pertence na constituição da essência do seu ser. É seu fundamento existencial.

Mediante isso, ter consciência geográfica é ter compreensão do Sentido de Localização, é ter para si a trama de relações de distâncias qualitativas de extensão variada a qual o ser está inserido, em quais nexos de ritmos está envolvido, ou seja, em quais tempos geográficos seu cotidiano está mergulhado. Em que contexto geográfico se insere seu Habitat. Representa a consciência das sucessivas geografias derivadas do processo histórico.

O homem em seu meio geográfico, objetivação sua, extensão inorgânica de si 
mesmo interagindo num contexto, numa determinada localização, o que representa sobreviver e existir nesse meio. Meio este que é sua realização, objetivação dos conteúdos da essência humana. Meio dotado de uma Geografia, um meio geográfico como quis nos fazer ver Demangeon ${ }^{12}$, um meio apropriado em sua objetividade e materialidade.

É aí nesse meio geográfico que o homem encontra o seu sentido de localização. Onde estou, e onde estão as outras coisas que compõe minha alteridade, qual sua distribuição, qual a distância que estão de mim, enfim, qual a Geografia que me cerca em sua extensão e que representação tenho dela: essa representação equivale ao sentido de localização, ou à consciência geográfica.

Todavia, resta indagar o quanto da relação homem-meio e da relação sociedadenatureza permite que se atinja essa consciência geográfica do sentido de localizaçãoe necessitamos de um contexto específico para ver isso.

E até aqui esta reflexão não apontou para um contexto específico, para nenhuma Geografia ou história específica, e há uma necessidade nesse sentido. Nasce do compromisso que imaginamos deva ter a ciência geográfica. E o cenário que mais nos importa é o mundo contemporâneo. Isso exige um esforço de observação de uma série de características específicas de natureza estrutural, que devem ser listadas, com intuito da investigação do fundamento ônticogeográfico do homem atual. Uma tarefa difícil, uma vez que, como observou Connor, "um dos problemas neste tipo de estudo é que [...] somos forçados a usar modos de compreensão que derivam dos períodos e conceitos sob exame $[\ldots]$ ". Ou então, que "na tentativa de entender nossos eus contemporâneos no momento presente, não há postos de observação seguramente afastados, nem na 'ciência', nem na 'religião', nem mesmo na 'história'. Estamos no e pertencemos ao momento que tentamos analisar, estamos nas e pertencemos às estruturas que empregamos para analisá-lo" (CONNOR, 1992, p. 13). Trata-se de um imenso esforço de natureza epistemológica o que se apresenta nessa tentativa.

A primeira e mais importante diz respeito às conseqüências que derivam da constatação do caráter alienado do Trabalho. A situação atual levou esse aspecto presente na relação homem-meio, sociedade-natureza, a patamares em que os significados só recentemente estão sedimentando aos olhos da análise. A perspectiva de compreensão está já apontada, em suas bases, a partir de Marx, expressas nos Manuscritos econômicofilosóficos de 1844. É desnecessário destacar a importância desse texto, bem como toda a reflexão que daí se desdobra em outros autores $^{13}$. A questão central agora é observar como fica o fundamento geográfico do ser do homem quando a relação entre ele e o meio se estabelece mediante o fato de que a sua objetivação Ihe é alienada. Um meio coisificado, que, portanto, se revela estanho. A partir disso, todas as características existenciais desse meio, que são as características da existência do próprio homem, possuem também caráter alienado. Ou seja, temos uma Geografia alienada, uma geograficidade estranha, por termos uma Geografia coisificada. Um exemplo disso? A cidade em sua Geografia que nos ameaça.

O homem de cotidiano de vida líquida, para nos inspirarmos em Bauman. Vivendo uma "era do vazio", nessa "cultura do capitalismo tardio", preenchida por regras que governam - "parque humano". Trata-se dos desdobramentos verificados a partir da presença do trabalho alienado ${ }^{14}$. disso?

E como fica o Sentido de Localização diante

Mas esse material - autores e temas fica para uma reflexão futura... Por hora ficamos por aqui. 


\section{Notas}

1 "Em busca de uma ontologia do espaço", in Geografia: teoria e crítica, Ruy Moreira (org.), Petrópolis, Vozes, 1982.

2 Não desconsideramos as polêmicas que estão no entorno dessa questão relativas a Aristóteles, bem como a evolução que o debate teve, passando por neoplatônicos, escolásticos e chegando, principalmente, até Kant. Mas pela brevidade imposta por este trabalho, estamos filiando-nos a essa possível interpretação do filósofo estargirita.

3 Para maiores detalhes a esse respeito: MARTINS, Elvio Rodrigues. "Lógica e espaço na obra de Immanuel Kant e suas Implicações na ciência geográfica", Geographia, n. 9, 2003.

${ }^{4}$ Interessante observar o seguinte: "De modo a evitar um erro não pouco freqüente, convirá sublinhar que se trata aqui da categoria filosófica de matéria, que não deve ser confundida com o conceito científico de matéria que está condicionado ao progresso científico, sofrendo com isso alterações ao longo da história" (BRANCO, 1989, p. 138-139). Ou então, matéria do ponto de vista da filosofia é a maior de todas as abstrações, e na ciência fala-se dos elementos da matéria em que as coisas em geral são compostas (elétrons, nêutrons etc.). Neste trabalho estamos perseguindo a noção filosófica.

${ }^{5}$ Isso foi mais extensamente desenvolvido no nosso trabalho "Da geografia à ciência geográfica e o discurso lógico", tese de doutorado, Faculdade de Filosofia, Ciências e Letras, Universidade de São Paulo (FFLCH/USP), 1996.

6 São notáveis também as observações acerca da confusão estabelecida entre "tempo" e "movimento", quando dentro desse contexto o "espaço" é tomado como estático. No capitulo VII, "Tempo e gênese em geografia", em "Propósitos e natureza da geografia", temos um excelente exemplo dessa problemática compreensão. O problema está que o "movimento" não é do "tempo" nem do "espaço", e sim daquele que tem essas três categorias como elemento de existência, ou seja, o movimento é do ente.

$7 \mathrm{E}$ isso continua sendo um problema para a linguagem, principalmente para a cartografia que quer dar conta dessa dinâmica geográfica.

8 Chamamos isso de "primeira geografia" por considerar somente esse momento inicial do processo de apropriação do mundo e de si feita pelo sujeito dentro desse ato da Descrição. As outras etapas, as "outras geografias", subseqüentes a essa primeira, também são encontradas na sua explicitação em Da geografia à ciência geográfica e o discurso lógico.

${ }^{9}$ Herder apud Ratzel (1914, p. 84).

10 Não há um existir sem a consciência, pois o existir é um ato que torna necessário a presença de duas partes, uma que afirma o que existe, e outra que é afirmada como existente. Mesmo que eu afirme a independência da existência diante da consciência, eu necessito da consciência para afirmar isso. O que não elimina a independência objetiva do que é externo a consciência. Existir é existir para, ou então "eu tenho a certeza por meio de um outro, a saber: da Coisa; e essa está na certeza mediante um outro, a saber, mediante o Eu" (HEGEL, 1992, p. 75).

11 A referência que aqui utilizamos é Lukács, nos trabalhos Introdução a uma estética marxista, e a própria Estética.

12 DEMANGEON, Albert. Problemas de geografia humana. Barcelona: Ediciones Omega, 1956.

13 Refiro-me aqui aos trabalhos de István Mészáros, "Marx: a teoria da alienação"; de Leandro Konder, "Marxismo e alienação"; e de Paulo Silveira, "Da alienação ao fetichismo - formas de subjetivação e objetivação".

14 As referências são: BAUMAN, Zygmunt. Modernidade Líquida. Rio de Janeiro: Jorge Zahar Editor, 2001; LIPOVETSKY, Gilles. A era do vazio: ensaios sobre o individualismo contemporâneo, Barueri: Manole, 2005; JAMENSON, Frederic. PósModernismo: a lógica cultural do capitalismo tardio. São Paulo: Ática, 1996; SLOTERDIJK, Peter. Regras para o Parque Humano. São Paulo: Estação Liberdade, 2000. 


\section{Bibliografia}

BRANCO, J. M. de. Dialética, ciência e natureza. Lisboa: Caminho, 1989.

CONNOR, S. Cultura Pós-Moderna: introdução às teorias do contemporâneo. São Paulo: Loyola, 1992.

DERRUAU, M. Tratado de geografia humana. Barcelona: Editorial Vicens-vives, 1964.

DESCARTES, R. Los princípios de la filosofia. Madrid: Alianza Editorial, 1995.

GEORGE, P. Sociologia e geografia. São Paulo: Forense, 1969.

A vida e obra de Max-Sorre. Boletim Geográfico do IBGE, n. 201, nov./dez. 1967.

HEGEL, G. W. F. Fenomenologia do espírito. Petrópolis: Vozes, 1992.

HELLER, A. Sociologia de la vida cotidiana. 2. ed. Barcelona: Ediciones Peninsula, 1987.

KANT, I. Princípios metafísicos da ciência da natureza. Lisboa: Edições 70, 1990.

LA BLACHE, P. V. Princípio de geografia humana. Lisboa: Edições Cosmos, 1954.
LUKÁCS, G. Introdução a uma estética marxista. Rio de Janeiro: Civilização Brasileira, 1968.

Estética. Barcelona: Grijalbo, 1982.

MOREIRA, R. Marxismo e geografia (a geograficidade e o diálogo das ontologias). Revista Geographia, n. 11, Pós-Graduação em Geografia, Universidade Federal Fluminense, 2004.

SANTOS, M. Espaço e sociedade. 2. ed. Petrópolis: Vozes, 1982.

SORRE, M. Recontres de la géographie et de la sociologie. Paris: Librairie Marcel Rivière et Cie., 1968.

Max Sorre. São Paulo: Ática, 1984. (Coleção Grandes Cientistas Sociais)

Ratzel, F. Geografia dell' uomo (antropogeografia). Torino: Fratelli Boca Editori, 1914.

Fayard, 1987
- La geógraphie politique. France:

Trabalho enviado em abril de 2007

Trabalho aceito em maio de 2007 
